\title{
Fibrinolytic markers could be useful predictors of severity in patients with pulmonary arterial hypertension: a retrospective study
}

Makoto Shoji ${ }^{*}$ (D, Taiju Matsui, Hideaki Tanaka, Kosuke Nomura, Hiroaki Tsujita, Yusuke Kodama, Shinji Koba, Youichi Kobayashi and Toshiro Shinke

\begin{abstract}
Background: The severity of pulmonary arterial hypertension (PAH) is classified based on mean pulmonary artery pressure (mPAP) levels. However, other markers have not been elucidated. Fibrinolytic markers, such as total plasminogen activator inhibitor-1 (tPAl-1) and thrombomodulin (TM), are known to reflect arterial endothelial function. However, the relationship between serum tPAI-1, TM and pulmonary circulation has not been completely determined.

Methods: This study included 100 consecutive patients (38 men), with a mean age of $68.9 \pm 12.0$ years, with cardiac diseases who underwent right heart catheterization. Serum coagulation and fibrinolytic marker levels were measured.

Results: The average mPAP value was $25.1 \pm 13.1 \mathrm{mmHg}$ for all patients. The mPAP levels revealed a significant positive correlation with serum tPAl-1 $(\rho=0.24, p=0.042)$ and uric acid $(\rho=0.29, p=0.0031)$ levels. In the group with mPAP levels less than $25 \mathrm{mmHg}(n=58$, ave. $17.3 \pm 4.3 \mathrm{mmHg}), \mathrm{mPAP}$ levels showed a significant positive correlation with serum tPA-1 $(\rho=0.34, p=0.034)$ and TM $(\rho=0.34, p=0.043)$ values. The mean tPAl-1 $(29.8 \pm 23.3$ $\mathrm{ng} / \mathrm{ml}, p=0.047)$ and uric acid $(5.7 \pm 1.8 \mathrm{mg} / \mathrm{dl}, p=0.026)$ levels were significantly less in those with lower mPAP levels. A multivariate analysis revealed that tPAI-1 alone was a significant independent characteristic marker of PAH (odds ratio $1.02,95 \% \mathrm{Cl} 1.000-1.036, p=0.034$ ).
\end{abstract}

Conclusions: These results indicate that serum TPAl-1 and TM may be useful predictors of severity, similar to mPAP in patients with PAH. They could be beneficial in predicting PAH among patients in the early stage of the disease.

Keywords: tPAl-1, Thrombomodulin, Pulmonary artery hypertension

*Correspondence: mashoji@hotmail.com

Department of Medicine, Division of Cardiology, Showa University School of

Medicine, 1-5-8 Hatanodai, Shinagawa-ku, Tokyo 142-8666, Japan

C C The Author(s). 2021 Open Access This article is licensed under a Creative Commons Attribution 4.0 International License, which permits use, sharing, adaptation, distribution and reproduction in any medium or format, as long as you give appropriate credit to the original author(s) and the source, provide a link to the Creative Commons licence, and indicate if changes were made. The images or other third party material in this article are included in the article's Creative Commons licence, unless indicated otherwise in a credit line to the material. If material is not included in the article's Creative Commons licence and your intended use is not permitted by statutory regulation or exceeds the permitted use, you will need to obtain permission directly from the copyright holder. To view a copy of this licence, visit http://creativecommons.org/licenses/by/4.0/ The Creative Commons Public Domain Dedication waiver (http://creativecommons.org/publicdomain/zero/1.0/) applies to the data made available in this article, unless otherwise stated in a credit line to the data. 


\section{Background}

The severity of pulmonary artery hypertension (PAH) is classified based on the mean pulmonary artery pressure (mPAP) levels that are evaluated by right heart catheterization (RHC). It is a fetal disease that is reported to have a poor prognosis despite the development in medication $[1,2]$. The mPAP has been established as an accurate prognostic marker for $\mathrm{PAH}$ in previous reports $[3,4]$. However, the patients require RHC to evaluate mPAP, which is an invasive procedure. Thus, noninvasive and alternative predictors for prognosis are needed.

The fibrinolytic marker, total plasminogen activator inhibitor-1 (tPAI-1) is a major inhibitor of plasminogen activator in plasma. It is stored in platelets and has several sources, including the vascular endothelium [5]. tPAI-1 is known to be associated with a proinflammatory atherosclerotic risk. Moreover, there are reports that tPAI-1 is independently associated with the degree of intima media thickness (IMT) [6, 7]. Thrombomodulin (TM) has an anticoagulant effect that is activating protein $\mathrm{C}$, and this is corroborated by reports about elevated blood levels of TM in patients with acute pulmonary embolism [8,9]. It is also known that TM is metabolized by the liver and excreted through the kidneys, and its level is elevated in a variety of diseases [10].

These fibrinolytic markers, tPAI- 1 and TM, are known to reflect arterial endothelial function. However, the relationship between serum tPAI-1, TM and pulmonary circulation has not been completely elucidated. In the present study, we aimed to evaluate if tPAI-1 and TM could be used as predictors of severity in patients with PAH.

\section{Methods}

We retrospectively reviewed the medical records of all consecutive patients who underwent RHC to assess cardiac function in Showa University Hospital between January 1, 2012, and March 31, 2018. This study was approved by the ethics committee of Showa University School of Medicine.

The details about patient history, physical examination, blood investigations, and echocardiography were evaluated. Patients with the following diseases that could affect serum tPAI-1 and TM levels were excluded from the study: (1) those on hemodialysis [11]; (2) those currently under treatment for malignant neoplasms; (3) those with hepatic failure [12, 13]; (4) those with congestive heart failure (CHF) NYHA grade III or more.

Blood samples were collected from patients at admission before RHC was performed. Fibrinolytic and coagulation marker levels, including tPAI-1, TM, D-dimer, thrombin-antithrombin complex (TAT), plasmin- $\alpha 2$ plasmin inhibitor complex (PIC), and prothrombin fragment $1+2$ (PTF $1+2)$ were also measured. The tPAI-1 level was measured using the latex agglutination test (JCA-BM9130, JEOL Ltd., Tokyo, Japan). The TM level was measured using an enzyme-linked immunoassay (ELISA) kit, AP-X (Kyowa Medex Co Ltd., Tokyo, Japan) [14].

\section{Statistical analysis}

Data are reported as mean \pm standard deviation. Continuous and categorical variables were compared using the Mann-Whitney $U$ test or chi-squared test, as appropriate. We performed Cox's stepwise logistic regression analysis to identify significant independent characteristic markers that were related to mPAP. We then calculated the odds ratios (ORs) and 95\% confidence intervals (CIs). Correlation analysis was performed using Spearman's rank correlation. We considered $p$ values less than 0.05 to be statistically significant. JMP software version

Table 1 Patient characteristics

\begin{tabular}{|c|c|}
\hline & Total Patients \\
\hline $\mathrm{N}$ & 100 \\
\hline \multicolumn{2}{|l|}{ Baseline characteristics } \\
\hline Age (years) & $68.9 \pm 12.0$ \\
\hline Male & $38(38 \%)$ \\
\hline BMI & $21.8 \pm 4.2$ \\
\hline Hypertension & $42(42 \%)$ \\
\hline Diabetes mellitus & $11(11 \%)$ \\
\hline Heart failure & $30(30 \%)$ \\
\hline Collagen diseases & $21(21 \%)$ \\
\hline Valvular diseases & $11(11 \%)$ \\
\hline Pulmonary embolism & $11(11 \%)$ \\
\hline Congenital heart diseases & $9(9 \%)$ \\
\hline Respiratory diseases & $7(7 \%)$ \\
\hline Ischemic heart diseases & $6(6 \%)$ \\
\hline Idiopathic pulmonary hypertension & $5(5 \%)$ \\
\hline Taking anticoagulants & $41(41 \%)$ \\
\hline \multicolumn{2}{|l|}{ Hemodynamics } \\
\hline Mean pulmonary artery pressure $(\mathrm{mmHg})$ & $25.1 \pm 13.2$ \\
\hline Pulmonary capillary wedge pressure $(\mathrm{mmHg})$ & $13.4 \pm 9.0$ \\
\hline Right ventricular pressure (mmHg) & $40.7 \pm 20.4$ \\
\hline \multicolumn{2}{|l|}{ Echocardiography } \\
\hline Ejection Fraction (\%) & $56.3 \pm 12.8$ \\
\hline Right Ventricular systolic pressure $(\mathrm{mmHg})$ & $51.2 \pm 21.5$ \\
\hline $\mathrm{BNP}(\mathrm{pg} / \mathrm{ml})$ & $464.8 \pm 1367$ \\
\hline Uric Acid (mg/dl) & $6.1 \pm 1.9$ \\
\hline Estimated GFR (ml/min) & $61.4 \pm 21.8$ \\
\hline
\end{tabular}

Data are presented as mean \pm SD or $\mathrm{n}(\%)$ $B M l$ Body mass index 
Table 2 Coagulation and Fibrinolytic markers

\begin{tabular}{ll}
\hline Makers & \\
\hline D-dimer $(\boldsymbol{\mu g} / \mathbf{m l})$ & $\mathbf{3 . 2 4} \pm \mathbf{1 1 . 5}$ \\
\hline Thrombomodulin $(\mathrm{FU} / \mathrm{ml})$ & $3.0 \pm 1.3$ \\
tPAl-1 $(\mathrm{ng} / \mathrm{ml})$ & $38.0 \pm 39.8$ \\
TAT $(\mu \mathrm{g} / \mathrm{l})$ & $6.33 \pm 11.1$ \\
PIC $(\mu \mathrm{g} / \mathrm{ml})$ & $1.5 \pm 2.8$ \\
PT F1 $+2(\mathrm{pmol} / \mathrm{l})$ & $258 \pm 217$ \\
\hline
\end{tabular}

Data are presented as mean \pm SD or $\mathrm{n}(\%)$

tPAl-1 Total plasminogen activator inhibitor-1; TAT Thrombin antithrombin complex, PIC plasmin-a plasmin inhibitor complex, PT F1 + 2

Prothrombin-fragment $1+2$

14.0 (SAS, Cary, NC, USA) was used for the statistical analysis.

\section{Results}

We reviewed the medical records of 111 consecutive patients who underwent RHC. Of these, 4 were excluded because of ongoing hemodialysis, 3 for currently undergoing treatment of a malignant neoplasm, 2 for hepatic failure, and 2 for worsening CHF (NYHA grade III or more). The remaining 100 patients were included in the study, and their clinical characteristics are shown in Tables 1, 2.

The mean age of the participants was $68.9 \pm 12.0$ years, and thirty-eight patients (38\%) were men. The underlying conditions comprised heart failure in 30 patients (30\%), collagen diseases in $21(21 \%)$, valvular diseases in $11(11 \%)$, pulmonary embolism in $11(11 \%)$, congenital heart diseases in 9 (9\%), respiratory diseases in $7(7 \%)$, ischemic heart diseases in $6(6 \%)$, and idiopathic pulmonary hypertension in 5 (5\%) (Table 1).

The average mPAP value was $25.1 \pm 13.1 \mathrm{mmHg}$. The mPAP values had significant positive correlation with serum tPAI-1 $(\rho=0.24, p=0.042)$ and uric acid $(\rho=$ $0.29, p=0.0031$ ) levels (Table 1, Fig. 1). After categorizing the patients based on their mPAP values, those in the group with average mPAP values less than $25 \mathrm{mmHg}$ $(17.3 \pm 4.3 \mathrm{mmHg})$ were observed to have a significant positive correlation between serum tPA-1 ( $\rho=0.34, p=$ $0.034)$ and TM $(\rho=0.34, p=0.043)$ levels and mPAP values (Fig. 2).

Both mean tPAI-1 $(29.8 \pm 23.3 \mathrm{ng} / \mathrm{ml}, p=0.047)$ and uric acid $(5.7 \pm 1.8 \mathrm{mg} / \mathrm{dl}, p=0.026)$ levels were significantly less in the group with lower mPAP values. A multivariate analysis, adjusted for age, gender, and BMI, revealed that tPAI-1 level alone was an independent characteristic marker (odds ratio 1.02, 95\%CI 1.0001.036, $p=0.034$ ) of the severity of PAH (Tables 3,4 ).

\section{Discussion}

The study results indicate that MPAP values have a significant positive correlation with serum tPAI-1 and uric acid levels in all enrolled patients. Among patients with mPAP values less than $25 \mathrm{mmHg}$ PAP, a significant positive correlation is observed with serum tPAI-1 and TM levels. The uric acid levels revealed a lower degree of association than the tPAI-1 levels, which was found to be

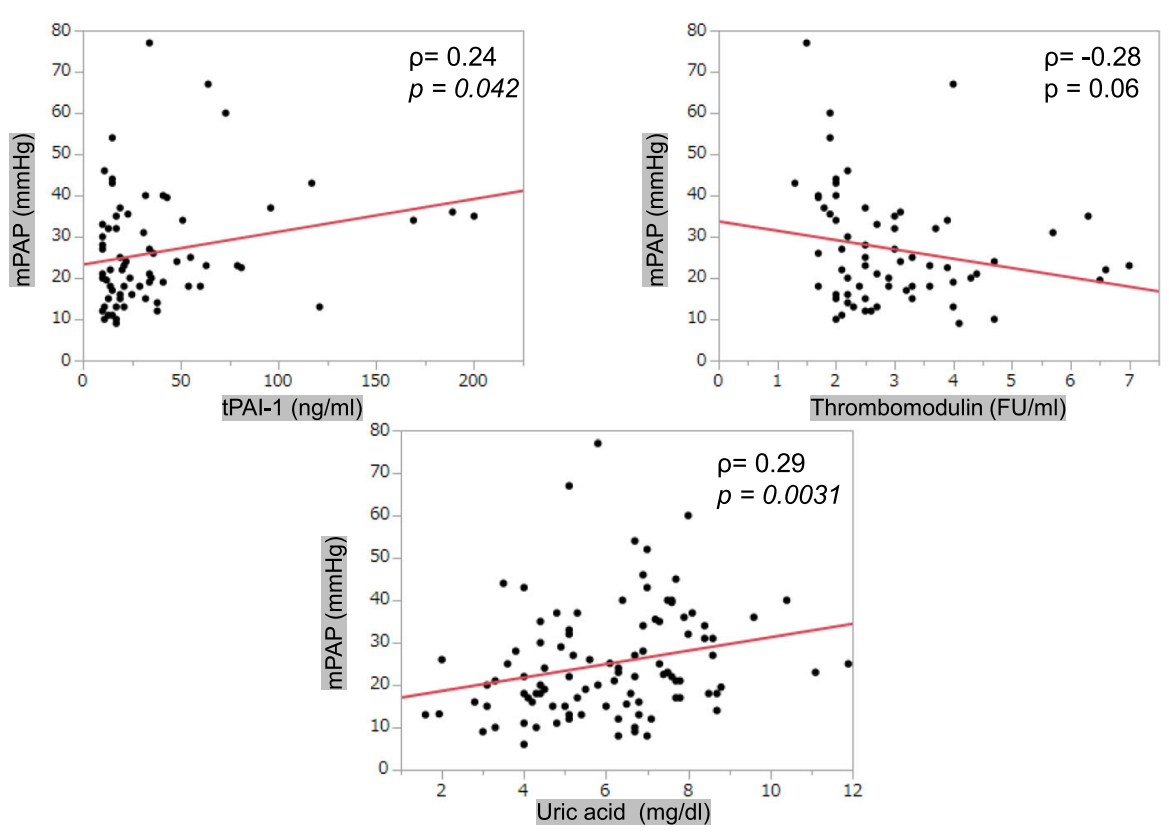

Fig. 1 Relationship between the mPAP levels and serum markers. A significant positive correlation is noted between the mPAP levels with serum tPAl-1 and uric acid values 

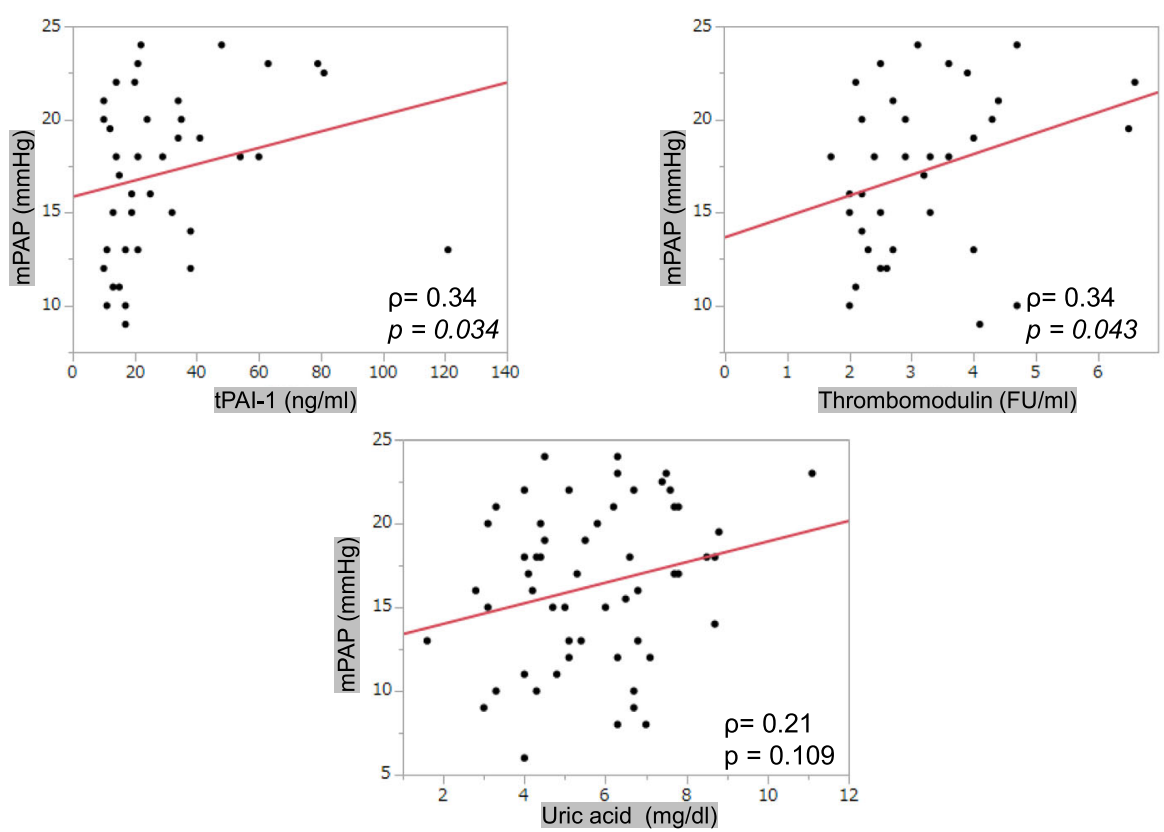

Fig. 2 Relationship between the mPAP and serum markers in those with levels less than $25 \mathrm{mmHg}$. The mPAP levels had significant positive correlation with serum $\mathrm{PPAl}-1$ and TM values

an independent marker in the group with lower mPAP values.

The severity of $\mathrm{PAH}$ in patients is indicated by the mPAP levels evaluated by RHC, which is an invasive examination. Therefore, less-invasive and reliable biomarkers that reflect the disease status accurately are desired. Serum uric acid is a traditional biomarker that reflects endothelial function and is a potential risk factor for arteriosclerotic change $[15,16]$. In the present study, uric acid levels revealed a significant positive correlation with mPAP values in all enrolled patients. This result is supported by the findings in some previous studies on atherosclerosis. However, in the group with mPAP values less than $25 \mathrm{mmHg}$, uric acid levels did not show a significant association with $\mathrm{mPAP}$.

Table 3 Comparison of biomarkers, $\mathrm{mPAP}<25$ or not

\begin{tabular}{llll}
\hline & mPAP $<\mathbf{2 5}$ & $\mathbf{m P A P} \geq \mathbf{2 5}$ & $\boldsymbol{P}$ value \\
\hline $\mathrm{N}$ & 58 & 42 & \\
D-dimer & $2.0 \pm 2.4$ & $4.9 \pm 18$ & N.S. \\
Thrombomodulin & $3.3 \pm 1.3$ & $2.6 \pm 1.1$ & N.S. \\
tPAI-1 & $29.8 \pm 23.3$ & $49.0 \pm 52.5$ & 0.047 \\
TAT & $5.0 \pm 9.2$ & $8.1 \pm 12.9$ & N.S. \\
PIC & $1.2 \pm 0.7$ & $1.9 \pm 4.1$ & N.S. \\
PT F1 + 2 & $262.7 \pm 171.1$ & $252.7 \pm 260.7$ & N.S. \\
BNP & $249.2 \pm 294.9$ & $752.2 \pm 2024$ & N.S. \\
Uric Acid & $5.7 \pm 1.8$ & $6.6 \pm 2.0$ & 0.026 \\
Estimated GFR & $63.9 \pm 22.5$ & $58.1 \pm 20.4$ & N.S. \\
\hline
\end{tabular}

According to the diagnostic criteria for $\mathrm{PAH}$, an mPAP level of $25 \mathrm{mmHg}$ is the cut-off value. Many clinicians focus on the preclinical stage of PAH predominantly, and the patients with mPAP levels less than 25 $\mathrm{mmHg}$ should be on intensive, careful follow-up because the response to treatment changes dramatically according to the state of the disease [1-4]. Hence, we focused our investigations in this group. The results indicate that unlike serum uric acid levels, tPAI-1 levels alone are an independent characteristic marker in the group with lower mPAP levels. Additionally, the mPAP levels reveal a significant positive association with serum tPAI-1 and TM but not uric acid levels, which means that these markers could be potential predictors of severity in patients with PAH in their early stages.

tPAI-1 is an inhibitor of plasminogen, which regulates the systemic fibrinolytic system, and the levels indicate microvascular injury due to various conditions, including diabetes mellitus [17]. It complements the activities of protein anticoagulants and endothelial-derived platelet

Table 4 Multivariate logistic regression adjusted to age, gender, BMl

\begin{tabular}{lcl}
\hline & \multicolumn{2}{c}{ Multivariate logistic regression } \\
\cline { 2 - 3 } & OR $(\mathbf{9 5} \% \mathrm{Cl})$ & $\boldsymbol{P}$ value \\
\hline tPAl-1 & $1.02(1.000-1.036)$ & 0.034 \\
UA & $1.07(0.793-1.434)$ & N.S. \\
\hline
\end{tabular}

Multivariate logistic regression adjusted to age, gender, BMI $O R$ Odds ratio, $\mathrm{Cl}$ Confidence interval 
inhibitors, such as proteins $\mathrm{C}, \mathrm{S}$, anti-thrombin III, and nitric oxide [5]. It is an endogenous defense mechanism for the prevention of atherosclerotic change, and there are some reports that the tPAI-1 levels are positively and independently associated with the degree of IMT $[6,7]$.

In contrast, TM is a factor that regulates the anticoagulation system by capturing thrombin and activating protein $\mathrm{C}$. Once damage to endothelial cells occurs, TM expressed on endothelial cells is cleaved from the membrane, and the product is detectable in a soluble form in circulating peripheral blood. This indicates that TM can be a marker of endothelial cell damage [18-20]. The mechanism in advanced PAH is speculated to involve an increased release of tPAI- 1 and TM from smooth muscle and endothelial cells caused by pulmonary vascular damage. This could result in elevated serum tPAI-1 and TM levels, as indicated in the present study. Ogawa et al. suggested that thrombin modulates pulmonary circulation through activation of the Akt pathway in smooth muscle cells among patients with $\mathrm{PAH}$ and chronic thromboembolic pulmonary hypertension (CTEPH) [21]. It also meant that TM levels could be altered due to endothelial dysfunction in the pulmonary artery. However, the concentration of circulating serum TM in peripheral blood would be saturated and the rest would be recruited by the kidney. In fact, there were no significant differences in the concentration of TM between the groups with mPAP levels less than or more than 25 mmHg.

We have demonstrated that mPAP levels have a significant positive correlation with serum tPAI-1 and TM but not uric acid values, which means that these markers could be potential predictors of severity in patients with $\mathrm{PAH}$, especially in their early stages with mPAP levels less than $25 \mathrm{mmHg}$.

This study has few limitations. First, this study was retrospective in nature with its inherent defects; therefore, a prospective study is needed in the future to confirm the results. Second, the population size is small, and the patients were from heterogeneous backgrounds. A larger sample size that includes a larger cohort of severe cases would allow a more reliable statistical evaluation. Third, not plasma but serum was used to evaluate tPAI-1 and other markers in this study based on previous study [14]. Serum is the supernatant of clotted blood where platelets have released their contents. Hence there is a possibility that the value of tPAI-1 is overestimated since it is a component of the platelet releasate.

\section{Conclusion}

These results reveal that serum tPAI- 1 and TM may be useful predictors that are similar to mPAP in patients with PAH. They could be beneficial in predicting severity in patients with $\mathrm{PAH}$, especially in their early stages.

\section{Abbreviations}

BMI: Body mass index; CHF: Congestive heart failure; Cl: Confidence intervals; CTEPH: Chronic thromboembolic pulmonary hypertension; ELISA: Enzymelinked immune sorbent assay; IMT: Intima media thickness; OR: Odds ratio; PIC: Plasmin-a2 plasmin inhibitor complex; PT F1 + 2: Prothrombinfragment 1 + 2; RHC: Right heart catheterization; SD: Standard deviation; TAT: Thrombin antithrombin; tPAl-1: Total plasminogen activator inhibitor-1; TM: Thrombomodulin

\section{Authors' information (optional) \\ Showa University School of Medicine, Department of Medicine, Division of Cardiology.}

\section{Authors' contributions}

M.S.: Design of the work, Drafting the manuscript. T.M.: Interpretation of data. H.T.: Interpretation of data. K.N.: Interpretation of data. H.T.: Interpretation of data. S.K.: Manuscript Drafting. Y.K.: Interpretation of data. T.S.: Manuscript Editing. The author(s) read and approved the final manuscript.

\section{Funding}

Not Applicable.

\section{Declarations}

Ethics approval and consent to participate

This manuscript was performed in accordance with Helsinki declaration. All patients' data were kept confidential. This study was approved by Showa University School of Medicine's ethical committee.

\section{Consent for publication}

The identity of the participants had not transpired.

\section{Competing interests}

Not Applicable.

Received: 10 February 2021 Accepted: 15 October 2021

Published online: 04 November 2021

\section{References}

1. Galiè N, Humbert M, Vachiery JL, Gibbs S, Lang I, Torbicki A, et al. 2015 ESC/ ERS Guidelines for the diagnosis and treatment of pulmonary hypertension: The Joint Task Force for the Diagnosis and Treatment of Pulmonary Hypertension of the European Society of Cardiology (ESC) and the European Respiratory Society (ERS): Endorsed by: Association for European Paediatric and Congenital Cardiology (AEPC), International Society for Heart and Lung Transplantation (ISHLT). Eur Heart J. 2016;37(1):67-119. https://doi. org/10.1093/eurheartj/ehv317.

2. Tamura $Y$, Kumamaru H, Satoh T, Miyata H, Ogawa A, Tanabe N, et al. Effectiveness and outcome of pulmonary arterial hypertension-specific therapy in Japanese patients with pulmonary arterial hypertension. Circ J. 2017;82(1):275-82. https://doi.org/10.1253/circj.CJ-17-0139.

3. Galiè N, Channick RN, Frantz RP, Grünig E, Jing ZC, Moiseeva O, et al. Risk stratification and medical therapy of pulmonary arterial hypertension. Eur Respir J. 2019;53(1):1801889. https://doi.org/10.1183/13993003.01889-2018.

4. Ogawa A, Ejiri K, Matsubara H. Long-term patient survival with idiopathic/ heritable pulmonary arterial hypertension treated at a single center in Japan. Life Sci. 2014;118(2):414-9. https://doi.org/10.1016/j.Ifs.2014.01.077.

5. Vaughan DE. PAI-1 and atherothrombosis. J Thromb Haemost. 2005;3(8): 1879-83. https://doi.org/10.1111/j.1538-7836.2005.01420.x.

6. Carratala A, Martinez-Hervas S, Rodriguez-Borja E, Benito E, Real JT, Saez GT, et al. PAl-1 levels are related to insulin resistance and carotid atherosclerosis in subjects with familial combined hyperlipidemia. J Investig Med. 2018; 66(1):17-21. https://doi.org/10.1136/jim-2017-000468.

7. Sakata T, Mannami T, Baba S, Kokubo Y, Kario K, Okamoto A, et al. Potential of free-form TFPI and PAI-1 to be useful markers of early atherosclerosis in a Japanese general population (the Suita study): association with the intimalmedial thickness of carotid arteries. Atherosclerosis. 2004;176(2):355-60. https://doi.org/10.1016/j.atherosclerosis.2004.05.017.

8. Li YH, Shi GY, Wu HL. The role of thrombomodulin in atherosclerosis: from bench to bedside. Cardiovasc Hematol Agents Med Chem. 2006;4(2):183-7. https://doi.org/10.2174/187152506776369953. 
9. Chen PS, Wang KC, Chao TH, Chung HC, Tseng SY, Luo CY, et al. Recombinant Thrombomodulin exerts anti-autophagic action in endothelial cells and provides anti-atherosclerosis effect in apolipoprotein E deficient mice. Sci Rep. 2017 Jun 12;7(1):3284. https://doi.org/10.1038/s41598-01703443-z.

10. Takano S, Kimura S, Ohdama S, Aoki N. Plasma thrombomodulin in health and diseases. Blood. 1990;76(10):2024-9. https://doi.org/10.1182/blood.V76.1 0.2024 .2024

11. Mizutani M, Yuzawa Y, Maruyama I, Sakamoto N, Matsuo S. Glomerular localization of thrombomodulin in human glomerulonephritis. Lab Investig. 1993;69(2):193-202.

12. Takatori M, Iwabuchi S, Ro S, Murayama M, Maeyama S, Uchikoshi T, et al. Increased serum levels and sinusoidal expression of thrombomodulin in acute liver damage. Thromb Res. 1999;93(3):113-20. https://doi.org/10.1016/ S0049-3848(98)00167-4.

13. Biguzzi E, Franchi F, Bucciarelli P, Colombo M, Romeo R. Endothelial protein $C$ receptor plasma levels increase in chronic liver disease, while thrombomodulin plasma levels increase only in hepatocellular carcinoma. Thromb Res. 2007;120(2):289-93. https://doi.org/10.1016/j.thromres.2006.09. 009.

14. Ochi A, Adachi T, Inokuchi K, Ogawa K, Nakamura Y, Chiba Y, et al. Effects of aging on the coagulation fibrinolytic system in outpatients of the cardiovascular department. Circ J. 2016;80(10):2133-40. https://doi.org/10.12 53/circj.CJ-16-0530.

15. Iribarren C, Folsom AR, Eckfeldt JH, McGovern PG, Nieto FJ. Correlates of uric acid and its association with asymptomatic carotid atherosclerosis: the ARIC study. Atherosclerosis Risk in Communities. Ann Epidemiol. 1996;6(4): 331-40. https://doi.org/10.1016/S1047-2797(96)00052-X.

16. Song M, Li N, Yao Y, Wang K, Yang J, Cui Q, et al. Longitudinal association between serum uric acid levels and multiterritorial atherosclerosis. J Cell Mol Med. 2019;23(8):4970-9. https://doi.org/10.1111/jcmm.14337.

17. Adly AA, Elbarbary NS, Ismail EA, Hassan SR. Plasminogen activator inhibitor1 (PAI-1) in children and adolescents with type 1 diabetes mellitus: relation to diabetic micro-vascular complications and carotid intima media thickness. J Diabetes Complicat. 2014;28(3):340-7. https://doi.org/10.1016/j. jdiacomp.2014.01.011.

18. Abe H, Okajima K, Okabe H, Takatsuki K, Binder BR. Granulocyte proteases and hydrogen peroxide synergistically inactivate thrombomodulin of endothelial cells in vitro. J Lab Clin Med. 1994;123(6):874-81.

19. Ishii H, Uchiyama H, Kazama M. Soluble thrombomodulin antigen in conditioned medium is increased by damage of endothelial cells. Thromb Haemost. 1991;65(05):618-23. https://doi.org/10.1055/s-0038-1648199.

20. Boffa MC, Karochkine M, Bérard M. Plasma thrombomodulin as a marker of endothelium damage. Nouv Rev Fr Hematol. 1991;33(6):529-30.

21. Ogawa A, Firth AL, Ariyasu S, Yamadori I, Matsubara H, Song S, et al. Thrombin-mediated activation of Akt signaling contributes to pulmonary vascular remodeling in pulmonary hypertension. Physiol Rep. 2013;1 (7): e00190.

\section{Publisher's Note}

Springer Nature remains neutral with regard to jurisdictional claims in published maps and institutional affiliations.

Ready to submit your research? Choose BMC and benefit from:
- fast, convenient online submission
- thorough peer review by experienced researchers in your field
- rapid publication on acceptance
- support for research data, including large and complex data types
- gold Open Access which fosters wider collaboration and increased citations
- maximum visibility for your research: over 100M website views per year
At BMC, research is always in progress.
Learn more biomedcentral.com/submissions

